\title{
Shake Table Studies on the Dynamic Response of Pile Supported Framed Structure in Soft Soil
}

\author{
Subramanya K G ${ }^{1, *}$, L Govindaraju², R Ramesh Babu ${ }^{3}$ \\ ${ }^{1}$ Department of Civil Engineering, Government Sri Krishnarajendra Silver Jubilee Technological Institute(GSKSJTI), Bengaluru, India \\ ${ }^{2}$ Department of Civil Engineering, University Visvesvaraya College of Engineering (UVCE), Bengaluru, India \\ ${ }^{3}$ Technical Consultant, Central Power Research Institute, Bengaluru, India
}

Received September 20, 2020; Revised November 26, 2020; Accepted December 6, 2020

\section{Cite This Paper in the following Citation Styles}

(a): [1] Subramanya K G, L Govindaraju, R Ramesh Babu, "Shake Table Studies on the Dynamic Response of Pile Supported Framed Structure in Soft Soil," Civil Engineering and Architecture, Vol. 8, No. 6, pp. 1313 - 1324, 2020. DOI: 10.13189/cea.2020.080615.

(b): Subramanya K G, L Govindaraju, R Ramesh Babu (2020). Shake Table Studies on the Dynamic Response of Pile Supported Framed Structure in Soft Soil. Civil Engineering and Architecture, 8(6), 1313 - 1324. DOI: 10.13189/cea.2020.080615.

Copyright $\bigcirc 2020$ by authors, all rights reserved. Authors agree that this article remains permanently open access under the terms of the Creative Commons Attribution License 4.0 International License

\begin{abstract}
Previous earthquakes have shown that structural damage depends not only on the behavior of the structure, but also on the foundation and subsoil below. The behaviour of pile foundations under seismic load is a very important factor affecting the performance of the structure. The primary aim of the research is to study the effect of the dynamic soil-pile-structure interaction on the response of a five-storey scaled-down model structure by conducting laboratory Shake table tests. The response of the model structure was investigated for both fixed base condition and supported by model piles embedded in soft clay. A rigid soil container with absorbing boundaries was used in the study along with a synthetic clay mix. The structural system was subjected to harmonic loading at different frequencies. From the experimental measurements, it can be observed that the soil pile structure system amplifies the lateral deflections and the storey drift of the superstructure in comparison with the fixed base structure. Building frames with varying height and lateral dimension were analysed numerically for both fixed and SSI with pile foundation in order to assess the effect of building configuration for the seismic response. The interaction of the soil pile structure system increases the lateral response of the structure. As the height of the structure increases, the amplification of response in SSI condition also increases, which can change the performance level of the structure, and hence Soil Pile Structure Interaction plays a significant role in the aseismic design of the structure.
\end{abstract}

Keywords Soil Pile Structure Interaction, Shake Table Tests, Scaled Model Tests, Seismic Response

\section{Introduction}

In the analysis of civil engineering structures, the super structure is usually analysed by treating it as independent from foundation and soil by providing fixity at the base on the assumption that no interaction takes place. The main purpose of the foundation is to safely transfer the loads on to the soil due to which the state of stress in soil is greatly altered which will intern affect the response of the structure. Hence it becomes imperative to consider soil foundation and structure as components of a single system for analysis and design.

It is evident from the past earthquakes that the damage to the structure not only depends on the behaviour of the super structure but also on the foundation and sub-soil below it. Since then, many researchers have studied the behaviour of the soil-pile-structure system subjected to dynamic loading. The behaviour of pile foundations under Seismic loading is a very important factor affecting the performance of the superstructure. Piles in firm soils have generally performed well during past earthquakes, while piles in soft and liquefiable soils have been a cause of major concern. 
The work on Soil pile structure was first started by Buragohain et al in 1977. Chi et al.in 2000 [24] developed a non-linear finite element methodology to study a soil pile structure system. In 2002 Yingcai studied the dynamic behaviour of tall buildings considering the Soil pile system using DYNAN computer program and concluded that fixed base analysis does not represent real seismic response. Later numerous works have been reported on the soil structure interaction of framed structures. Ingle and Chore [25] have presented a methodology using three-dimensional finite element analysis for building frames supported by pile groups.

There are several studies which report the experimental analysis of SSI. Boulanger et al. [12] evaluated dynamic p-y analysis conducting centrifuge model tests over wide range of shaking intensities and earthquake motions and found reasonable agreement with test results. Durante et al. [6] experimental investigations are carried out to access the effects of pile configurations on the response of superstructure under harmonic excitations using shake table. Hussien et al. [9] performed geotechnical centrifuge experiments to evaluate the dynamic response of systems with varying pile configurations and observed both kinematic and inertial components. Martakis et al. [19] conducted a series of dynamic centrifuge experiments to investigate the influence of structural parameters and soil properties on SSI effects by conducting a series of dynamic centrifuge experiments. Experimental studies on soil-structure interaction are either dynamic centrifuge model tests or shake table tests. Though there are very few studies on full-scale dynamic tests, such as the test of a railway bridge portal frame by Zangeneh et al. [20]. Full-scale model tests are usually complex in nature and expensive. Researchers have been involved in scaled model tests and numerical modelling approaches to analyse SSI effects.

This paper attempts to conduct soil pile structure interaction of a scaled model experiment using shake table and compare with numerical analysis of prototype structure. The building frames with varying height and lateral dimension are also analyzed for both fixed and SSI (pile foundation) in order to assess the effect of building configuration on the seismic response.

\section{Experimental Method}

It is always very difficult to analyse the prototype or full-scale model in a laboratory. Hence testing the critical component of the structure by simulating the field conditions is usually done. In contrast to element tests, model tests are usually conducted considering a small-scale physical model that represents a full-scale prototype structure.

Model tests for dynamic analysis can be divided into those performed using shake tables under the gravitational field of the earth (1g model tests) and those are performed using geotechnical centrifuge under increased gravitational fields. Shake tables are commonly used to obtain the structural responses to ground motions but geotechnical-focused problems presents challenges. Model tests on soil requires an infinite soil medium to be modelled with a finite boundary, which is achieved by confining the soil in a model soil container.

\subsection{Similitude Analysis}

Similitude analysis is a mathematical framework that relates the quantities that are measured in scaled model to the prototype. "Depending on the degree to which the scaled models meet the requirements of similitude, the models are classified as True, adequate and distorted models" [17]. The true model satisfies all the necessary requirements of similitude. In an adequate model, the first-order (controlling) parameters maintain similarity while those which the second order parameters are allowed to deviate. The second-order parameters are those that do not affect the prediction significantly. The selection of first-order and second-order parameters is dependent on the problem being investigated. Distorted model is one in which one or more first-order parameters in the similitude analysis deviate. Several researchers have given different similitude relations for a different type of experimental investigations. Table 1 gives the similitude scale factors for the earthquake response of structures. Here $\lambda$ and EI are scaling factor and flexural rigidity respectively.

Table 1. Summary of Similitude factors for Earthquake Response of Structures [14]

\begin{tabular}{cc}
\hline Parameter & Scaling Relationship \\
\hline Mass density & 1 \\
Force & $\lambda^{3}$ \\
Modulus & $\lambda$ \\
Acceleration & 1 \\
Shear wave velocity & $\lambda^{1 / 2}$ \\
Time & $\lambda^{1 / 2}$ \\
Frequency & $\lambda^{-1 / 2}$ \\
Length & $\lambda$ \\
Stress & $\mathrm{E}$ \\
Strain & 1 \\
EI & $\lambda^{5}$ \\
\hline
\end{tabular}

A constant scaling factor is to be maintained for the materials to be used for modelling the structure. Most of the investigations, material used for the model is not the same as that of the prototype, which conflicts the true replica of the model as it does not satisfy the similitude factor. Lu et.al [11] presented a similitude formula considering different similitudes for material and other dimensional parameters.

Meymand [13] and Moss et al. [22] have explained that 
similitude theory cannot be directly applied to the complete system of soil and structure to achieve model similarity. Hence it can be inferred that in most of the similitude analysis on soil-structure interaction, it is difficult to achieve a true model. In similitude analysis on soil structure interaction, the similitude of superstructure and substructure is generally taken into account. However, the similitude for soil is often ignored or not accounted for completely due to its complexity.

Scaled models for soil structure interaction studies are usually done with a different material than that of the prototype. Goit et al. [21] modelled the super structure with steel and substructure with acrylic material.

Similar to that of super structure model, piles must also be subjected scaling principles to achieve this principal governing factors like slenderness ratio, flexural stiffness and moment-curvature relationship. Based on the L/D ratio ( $\mathrm{L}$ and $\mathrm{D}$ are length of pile and Diameter of pile) and flexural stiffness, the material and section of the pile needs to be selected. Previous researches have used different types of material like aluminum tubes, steel bars, concrete and acrylic material.

In order to incorporate dynamic scaling for soil properties, Aslant S et al. [14] and Syed Hamid [5] have designed a synthetic clay mix with adequate bearing capacity in order to meet the scale model criteria for shear wave velocity of the soil.

In the present study, scaled model tests have been carried out using uniaxial Shake table facility at Earthquake Engineering laboratory of UVCE, Bangalore University, Bangalore. The size of the Shake table platform is $1 \mathrm{mX} 1 \mathrm{~m}$, with a maximum payload of $100 \mathrm{Kg}$. The Shake table can be operated with a frequency range of $0.05 \mathrm{~Hz}-25 \mathrm{~Hz}$ with a displacement of $1-10 \mathrm{~mm}$ with a data acquisition system (DAQ)

\subsection{Prototype and Scaled Model}

Table 2. Geometric and material properties of the structure

\begin{tabular}{|c|c|}
\hline Component & Description \\
\hline Number of storey & 5 \\
\hline Number of bays in both ' $x$ ' and ' $y$ ' direction & one \\
\hline Bay width & $4 \mathrm{~m} \mathrm{c} / \mathrm{c}$ \\
\hline Storey height & $3 \mathrm{~m}$ \\
\hline Beam size & $0.325 \mathrm{~m} \times 0.325 \mathrm{~m}$ \\
\hline Column size & $0.325 \mathrm{~m} \times 0.325 \mathrm{~m}$ \\
\hline Slab thickness & $0.125 \mathrm{~m}$ \\
\hline Concrete & M30 \\
\hline
\end{tabular}

In the present study, a symmetric building space frame of one bay 5 storey with regular plan is considered, as show in Fig 1. The building is analysed and designed for earthquake Zone V as per IS 1893 [23]. The details of building frames considered for the study are given in Table 2. The space frame is modelled in ETABS using one dimensional element for beams and columns and slab is modelled as 2D element. A uniformly distributed
Imposed load of $3 \mathrm{KN} / \mathrm{m}^{2}$ was applied, modal analysis and time history analysis have been carried out to find its dynamic properties and the response to the ground excitation.

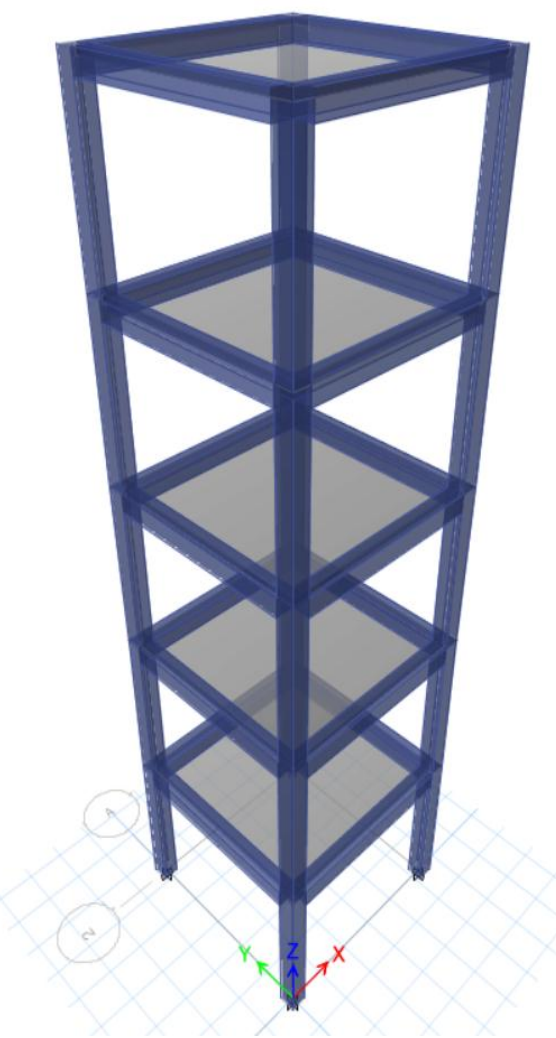

Figure 1. Three-dimensional view of structure selected

Modal analysis was performed to calculate the period, natural frequency, stiffness and mass participation in the fundamental mode. The time period and natural frequency of the system is given in Table 3 .

Table 3. Time Period \& Natural Frequency of prototype

\begin{tabular}{ccc}
\hline Mode & Time period $(\mathbf{s e c})$ & Frequency $(\mathbf{H z})$ \\
\hline Mode 1 & 0.64 & 1.56 \\
Mode 2 & 0.64 & 1.56 \\
Mode 3 & 0.56 & 1.79 \\
\hline
\end{tabular}

Based on the results of modal analysis, the structure is scaled to 1:30 for dynamic model studies. The similitude factors adopted for the study is shown in Table 1. The scaled model parameters are found by satisfying the equivalent stiffness in the fundamental mode direction and keeping the mass density ratio as same in prototype as well as in the scaled model. Numerical analysis was performed to match the similitude parameters by trial and error to match the stiffness and mass density ratio by varying the cross section of the column and the thickness of the slab. Lumped symmetrical mass was also considered at each floor level to achieve the same mass density ratio of the model and prototype. The properties of the scaled model are tabulated in Table 4. 
Table 4. Properties of Prototype and Scaled Model

\begin{tabular}{ccc}
\hline Parameter & Prototype & Scale Model 1:30 \\
\hline Time period & $0.64 \mathrm{Sec}$ & $0.12 \mathrm{Sec}$ \\
Frequency & $1.56 \mathrm{~Hz}$ & $8.5 \mathrm{~Hz}$ \\
Super structure & Concrete & Aluminium \\
material & $325 \mathrm{mmX} 325 \mathrm{~m}$ & $12 \mathrm{mmX} 2 \mathrm{~mm}$ \\
Size of column & $125 \mathrm{~mm}$ & $8 \mathrm{~mm}$ \\
Slab thickness & & \\
\hline
\end{tabular}

The material for the fabrication of the model is taken as aluminium to match the mass and low stiffness requirement for a scale of 1:30. The connection between the slab and column is achieved by using $4 \mathrm{~mm}$ bolt. A base plate is provided for mounting the model on shake table. The beams are eliminated in the model by achieving the equivalent stiffness required there by overcoming the fabrication difficulty for higher scale. The working drawing of the model is shown in Figure 2.

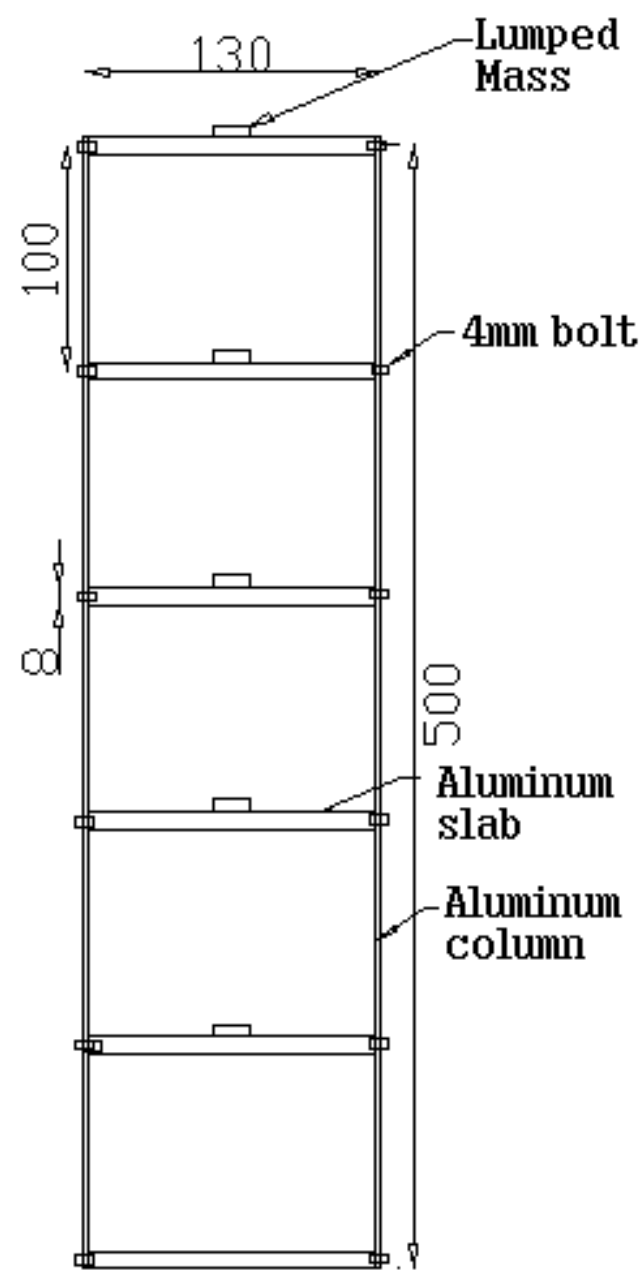

Figure 2. Details of scaled model

\section{Shake Table Tests on the Fixed-base Model structure}

The experiment was conducted by fixing the model to the shake table by means of rigid bolt connection. Impulse test was conducted to find the fundamental frequency. The shake table was subjected to motion with sine sweep \& frequency is varied from $1 \mathrm{~Hz}$ to $12 \mathrm{~Hz}$, in order to obtain the resonant frequency and response for harmonic loading at different frequencies. The resonant frequency of the scaled model was found to be $8.6 \mathrm{~Hz}$ which was in good agreement with the required frequency of $8.5 \mathrm{~Hz}$. Storey displacements and accelerations were recorded for each harmonic excitation.

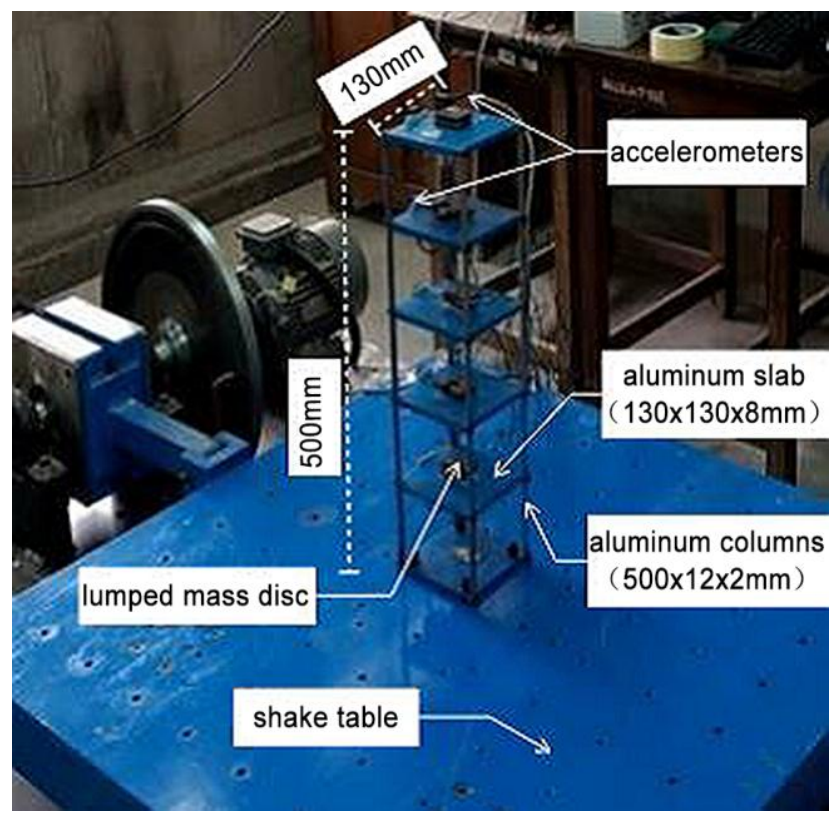

Figure 3. Shake table experiment on fixed base structure

\section{Modeling of Soil Pile System}

\subsection{Model Soil Container for SSI}

Model tests on soil requires an infinite soil medium to be modelled with a finite boundary, however, the confining effect as in continuous medium needs to be incorporated in the soil model. This is achieved by confining the soil in a model container. Many researchers have used laminar container which normally contains an external frame with a stack of laminae supported by bearings.

Initially, researchers conducted experiments using rigid soil container. The drawback of the rigid soil container is that the waves get reflected from the walls of the container due to the artificial boundary. Numerical studies have reported that zones up to 1.5 to 2 times the height of the container close to walls are affected by artificial boundary and recommended that the ratio of the length to height of the rigid soil container should be more than 4 in order to minimize the artificial boundary effect [10]. To overcome the drawbacks of the rigid container, several researchers have studied and proposed alternatives or modifications to 
the rigid container. Bhattacharya et al. [10] used a flexible boundary in a rigid tank in order to limit the reflection of waves from the boundaries. The flexible boundary is introduced by gluing a soft material like sponge along the end walls of the container

In the present study, a rigid soil container made of acrylic material is used for soil pile structure interaction studies. The size of the tank is so designed that the length of the tank is five times the width of the model and also a flexible boundary is introduced by gluing a very low-density sponge along the end walls of the container in order to minimize the boundary effect.

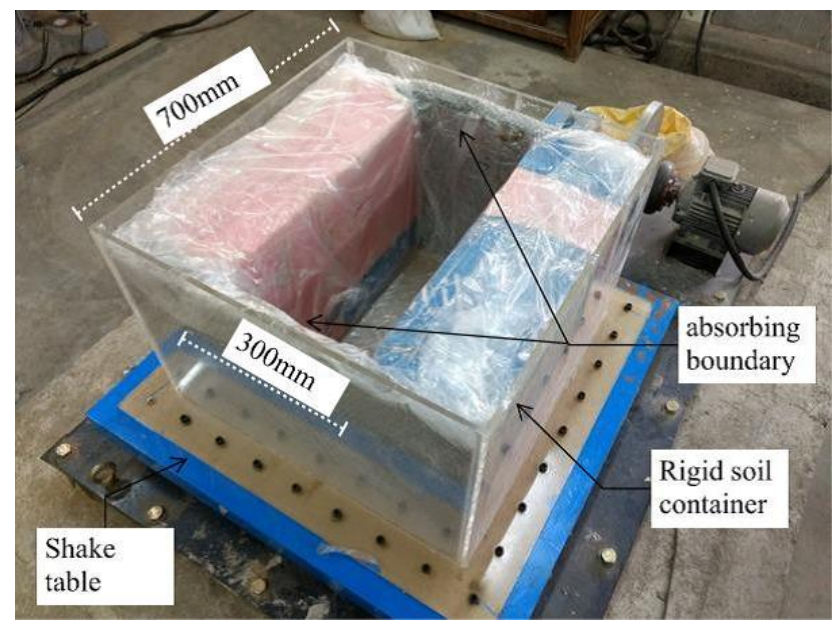

Figure 4. Rigid soil container with absorbing boundaries

\subsection{Soil Mix}

Based on the scaling relation, the model soil should have a shear-wave velocity of $36 \mathrm{~m} / \mathrm{s}$ and density of 1,480 $\mathrm{kg} / \mathrm{m}^{3}$ to achieve a dynamic similitude with the prototype soil of density $1480 \mathrm{~kg} / \mathrm{m}^{3}$ and shear wave velocity of $200 \mathrm{~m} / \mathrm{s}$. Meymand et.al.[13] reported that a reconstructed soil may not have required bearing capacity and the design shear wave velocity, whereas a synthetic clay mix can offer required bearing capacity underneath the structural model and can also meet the requirement of the shear-wave velocity. An artificial synthetic clay mix was designed using kaolinite clay, bentonite, Class F fly ash, lime, and water by Aslan et.al [14] in order to find the most suitable soil mix for laboratory investigation. The same mix proportions were used with trials and found the density of $1480 \mathrm{~kg} / \mathrm{m} 3$. The density and the undrained shear strength of the clay mix were in good agreement with the values as reported by the author. Furthermore, the same clay mix with the proportion of $60 \%$ kaolinite clay, $20 \%$ bentonite, $10 \%$ Class F fly ash \& $10 \%$ lime with $100 \%$ water was used for the synthetic clay mix.

\subsection{Model Pile Foundation}

Similar to the superstructure, the model piles must also be subjected to scaling criteria. Model piles not only satisfy the overall pile slenderness, relative spacing, and consequent group interaction but also satisfy the scaling flexural rigidity Thus, by considering the geometric scaling factor of 1:30, model square piles with sides $12 \mathrm{~mm}$ and a length of $280 \mathrm{~mm}$ with acrylic material with a young's modulus of $3 \mathrm{GPa}$ was considered.

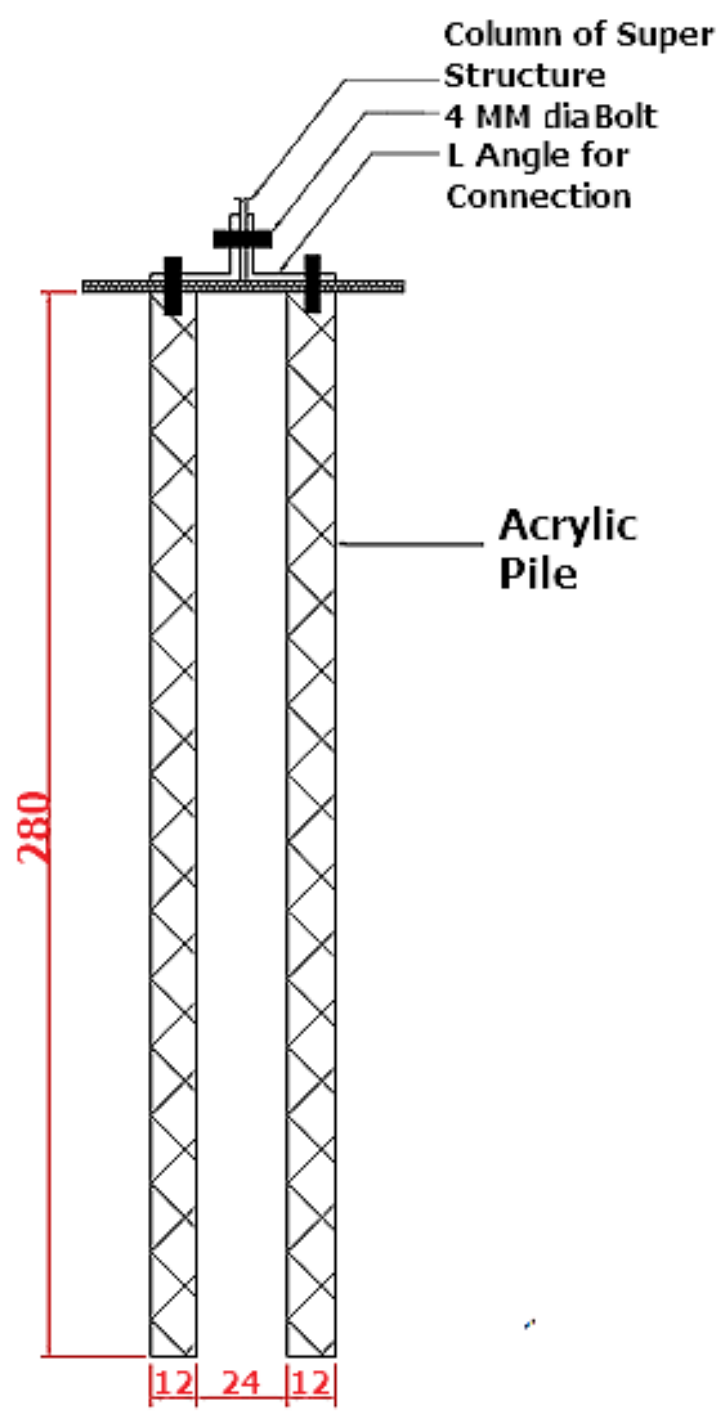

Figure 5. Model pile configuration

\section{Shake Table Tests on the Soil Pile Structure Model}

The second stage of the Shake table test was to study the effect of the soil-pile-structure interaction on the dynamic response of the structural system in comparison with the fixed-base tests. As mentioned before acrylic material was used to build the model piles and pile cap. The pile cap and the piles were connected with screws and intern the pile cap was connected to the column. The strain gauges were placed near pile head. In order to ensure the workability of the strain gauges, they were sealed with a waterproof cover. The entire model was installed carefully ensuring all the connections. 


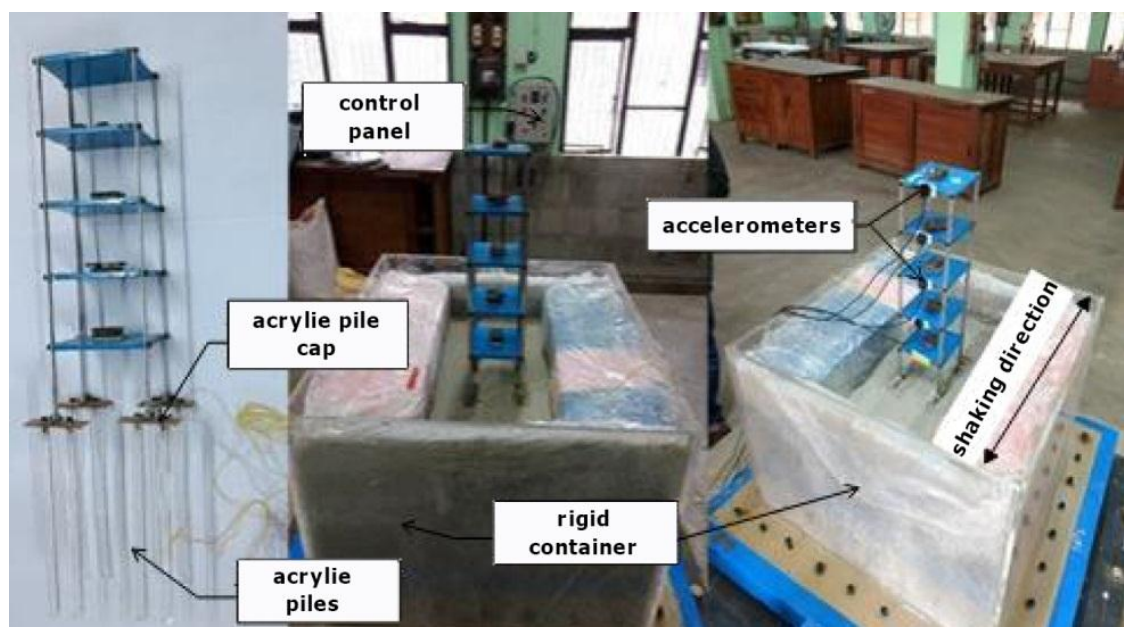

Figure 6. Experimental setup for SSI analysis

After connecting all of the components of the system, including the rigid container, synthetic soil, piles, pile cap and superstructure, the accelerometers were placed on the model structures at each floor level and in addition to that accelerometer placed at the pile cap. The final setup of the tests, including accelerometers at various levels of the structural model for the 5-story building supported on pile group in soft clay is shown in Figure 6.

Similar Shake tests were carried out with the sine sweep to the Structural system. The fundamental natural frequency of the soil-pile-structure model from the test was measured to be $8.00 \mathrm{~Hz}$ for the 5 -storey model structure. The structure was applied with base excitation at different frequencies. Figure 7 shows the base acceleration at resonant frequency.

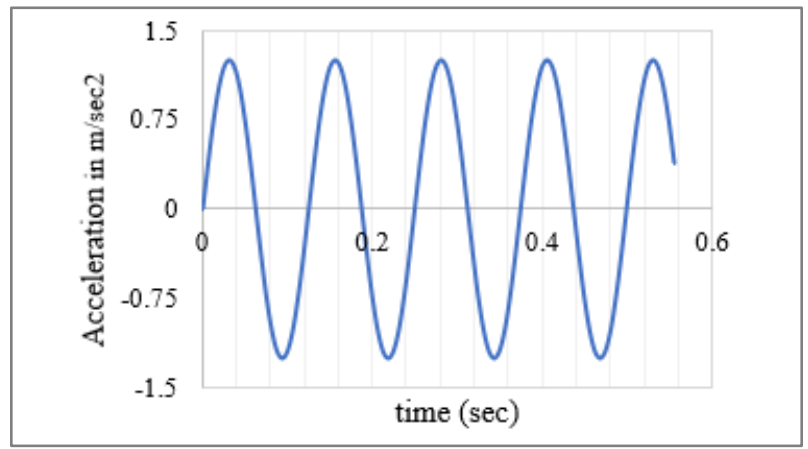

Figure 7. Base Excitation (harmonic load)

\section{Nmerical Modelling and Analysis}

Numerical modelling and analysis of prototype structure with fixed base and Soil Structure interaction analysis are performed by finite element method using SAP 2000 and are compared with the scaled experimental response. In addition to the modelling of superstructure, the substructure and soil are modelled as a continuum model[3]. The pile cap, pile and soil are modelled with 8 noded three-dimensional Solid element and node to node connections were ensured at the interface soil and pile since its cohesive soil. The dimensions of the soil mass considered are greater than five times the model width in order to minimize the boundary effect. The periphery of the soil boundary was constrained in translation degrees and the base of the soil mass is fixed assuming that the soil below is hard strata [4]. The three-dimensional numerical model of prototype structure is shown in Fig 8. Building frames with varying height and lateral dimension were analysed numerically for both fixed and SSI with pile foundation in order to assess the effect of building configuration for seismic response

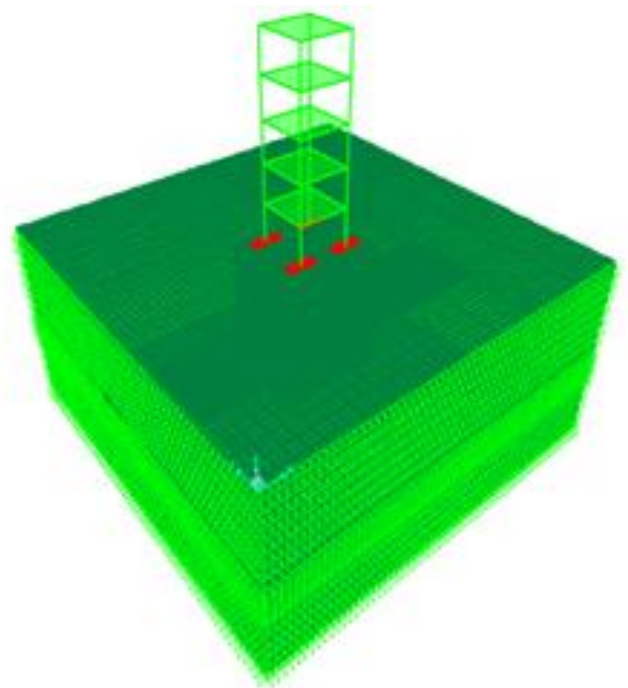

Figure 8. Numerical Model of Soil Pile Structure

\section{Results and Discussion}

The response of the model for harmonic excitation was recorded in terms of lateral displacement and acceleration. Figure 9 shows the response of the model in the fixed base condition for harmonic load at different frequencies. It can be observed that the response is higher at the resonant frequency of $8.6 \mathrm{~Hz}$ which is very much close to 
the required frequency of $8.5 \mathrm{~Hz}$.

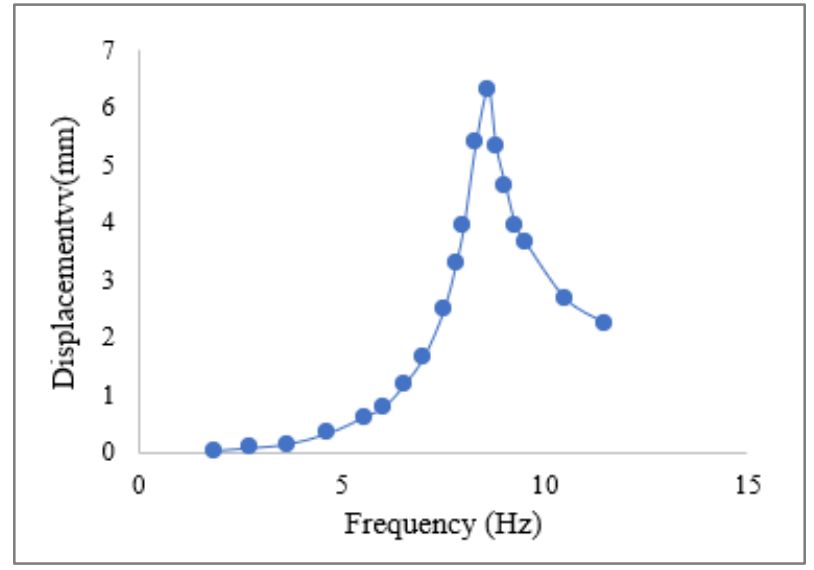

Figure 9. Frequency response of scaled model (Fixed base)

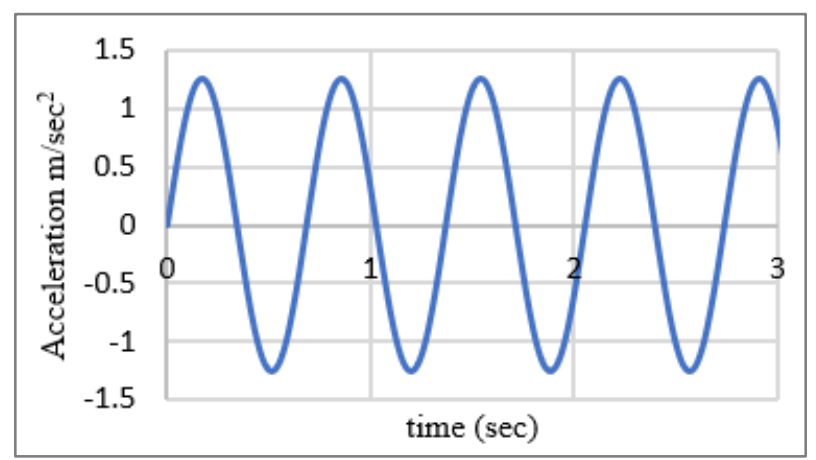

Figure 10. Scaled Base Acceleration

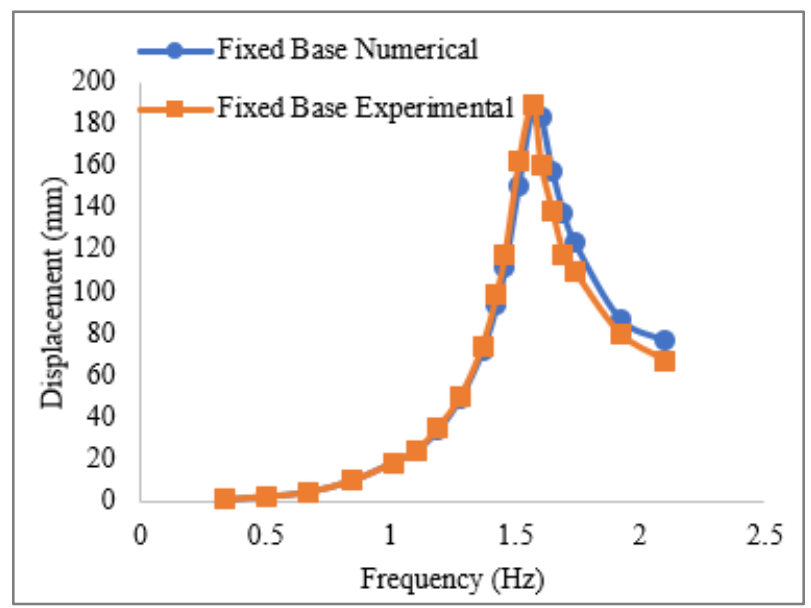

Figure 11. Top storey displacement v/s frequency for fixed prototype building

A numerical analysis was done similar to that of the experiment by applying scaled harmonic load and the top storey displacement was calculated for prototype model. As shown in Fig 10, the harmonic excitation which was applied for the prototype model was scaled, which was used for the numerical analysis. The damping for the model was calculated by half power bandwidth method and the same was incorporated in the numerical model. The response of the model is scaled to prototype by means of scaling factor and is compared with numerical analysis.
Fig 11 shows the comparison of scaled response experimental analysis and the prototype numerical analysis. The frequency and top storey displacement of experimental values are in good agreement with the numerical value

The next set of experiments were carried out by considering the soil foundation structure system. The superstructure was connected to the model piles and pile cap by means of an $\mathrm{L}$ angle and screws and then it was embedded in synthetic clay placed in a rigid soil container with absorbing boundaries. The soil container was placed on shake table and was connected using bolts. Similar experiments were conducted on the Soil pile structure system. The impulse test showed that the resonant frequency of the system to be $8 \mathrm{~Hz}$.

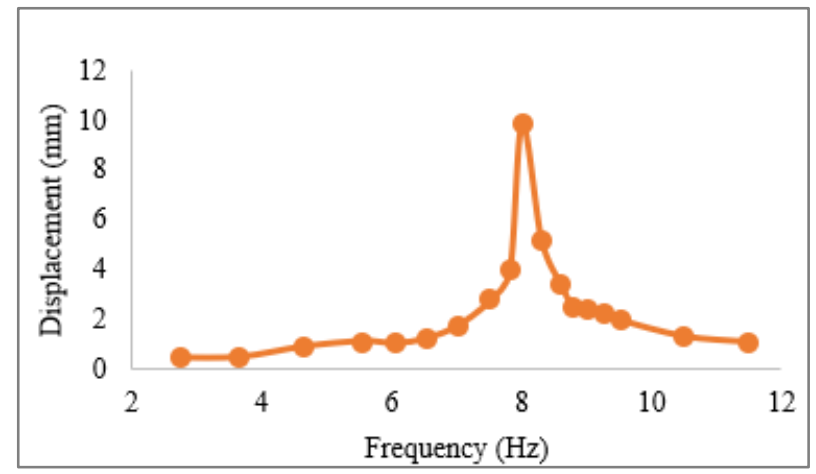

Figure 12. Top storey displacement v/s frequency for scaled model (SSI condition)

According to the frequency response curve shown in Figure 12, the frequency for soil pile structure interaction is found to be $8 \mathrm{~Hz}$ and that of fixed base is $8.6 \mathrm{~Hz}$. Thus, it shows that the soil pile structure system alters the fundamental dynamic property of the structure there by altering the response of the superstructure to the dynamic loading. Figure shows the increase in top storey displacement and time period for SSI condition compared to fixed base condition of the model.

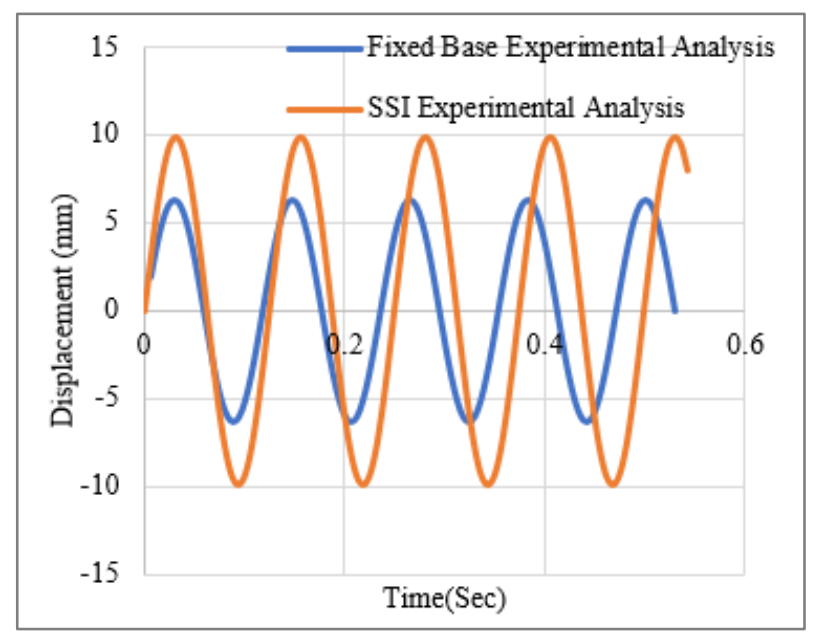

Figure 13. Top storey displacement in time domain for fixed base and SSI condition 


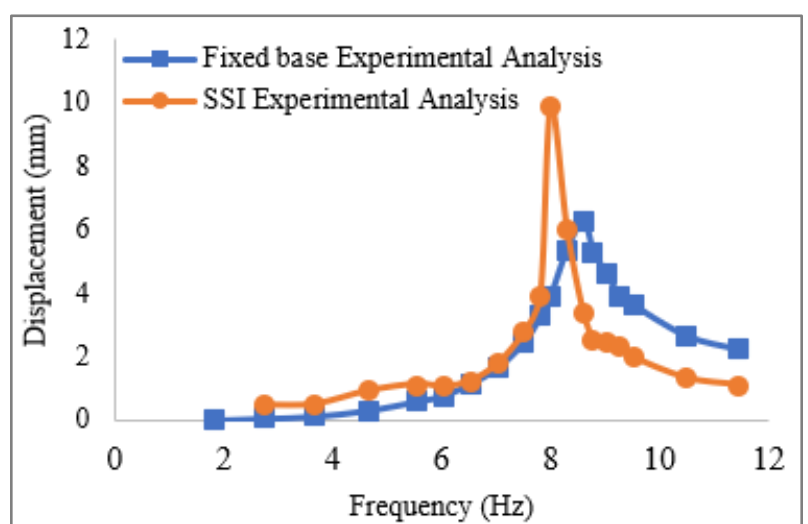

Figure 14. Top Storey displacement v/s frequency for fixed base and SSI condition

The top storey displacement of the soil pile system shows $60 \%$ more compared to fixed base at the resonance condition. The rocking component plays an important role in lateral deformation of the super structure. Rocking angle was calculated based on the vertical deformation of the pile cap and the contribution of lateral displacement of the structure due to rocking was found to be about $18 \%$ while the remaining is due to the distortion. While the SSI acceleration curve shows $66 \%$ amplification compared to that of fixed base condition.

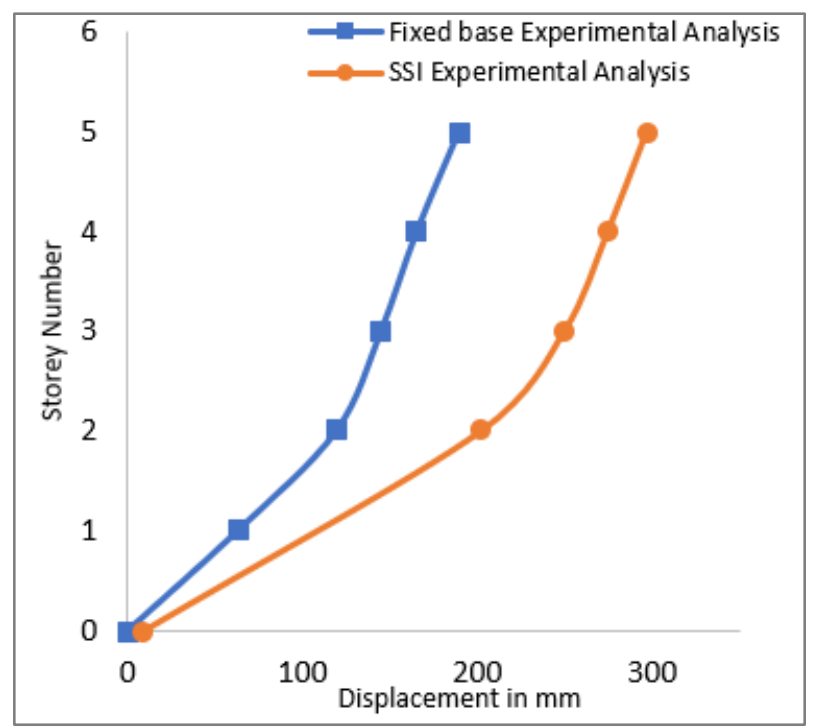

Figure 15. Storey Displacement at Resonance

Based on the storey-displacement, storey drifts were calculated as per IS 1893 [23] and presented in Figure 16. It can be observed that the storey drift has increased in SSI model compared to the fixed base condition. The values of storey drift have crossed the limiting value as per the IS 1893 [23] codal provisions, it indicates that the model might have inelastic zone.

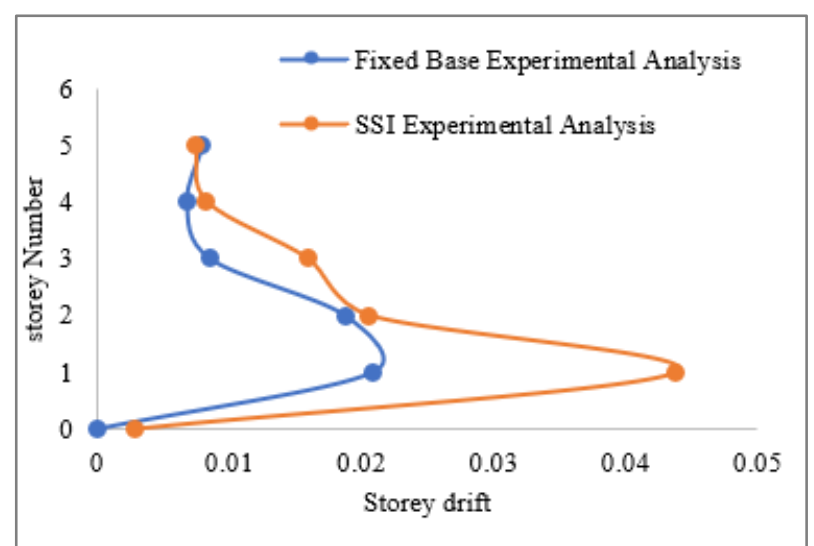

Figure 16. Storey drift at resonance

An attempt is made to model the soil pile structure system numerically. Modal analysis was carried out to compare the natural frequency of the SSI prototype and model. The Experimental frequency for SSI was found to be $8 \mathrm{~Hz}$ and the scaled frequency of the prototype is $1.46 \mathrm{~Hz}$, whereas the frequency corresponding to the Shake direction was found to be $1.2 \mathrm{~Hz}$ in the numerical method.

Time history dynamic analysis was performed to the SSI prototype numerical model by applying the scaled harmonic load that of the scaled model and the response were plotted in terms of the frequency response curve, storey displacement and compared with the experimental results.

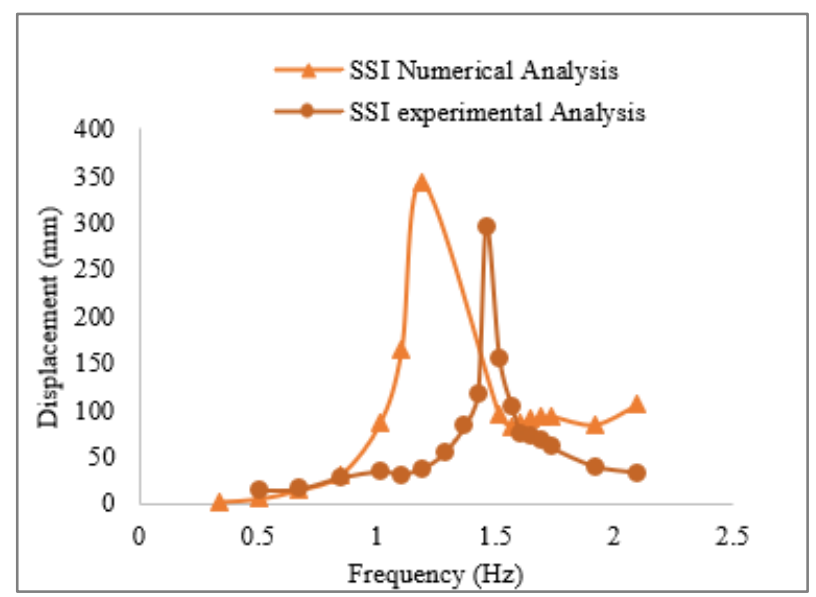

Figure 17. Top storey displacement (SSI) v/s frequency (Numerical \& Experimental)

The Figure 17 shows the numerical and experimental response of SSI model, the numerical trend matches with the experimental displacement with a deviation of $13 \%$. The storey displacement of numerical analysis is very much close to experimental results. 


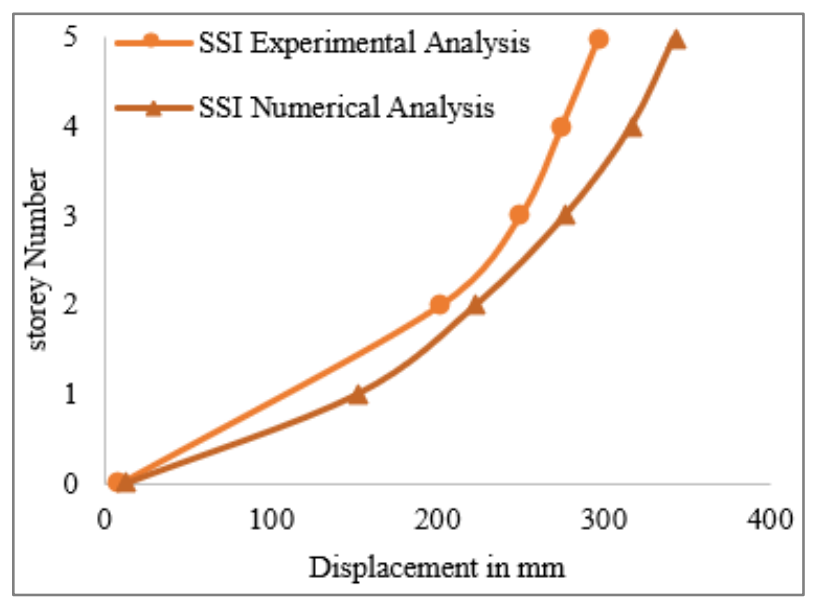

Figure 18. Storey displacement at resonance (experimental and numerical)

To understand the behavior of the model under Real ground motion, a time history analysis has been carried out for both the fixed base and SSI Numerical model. As shown in Figure 19, a time history load of the earthquake of Bhujj(2011) having a time step of 0.005 seconds with a peak ground acceleration of $0.1 \mathrm{~g}$ has been considered for the analysis.

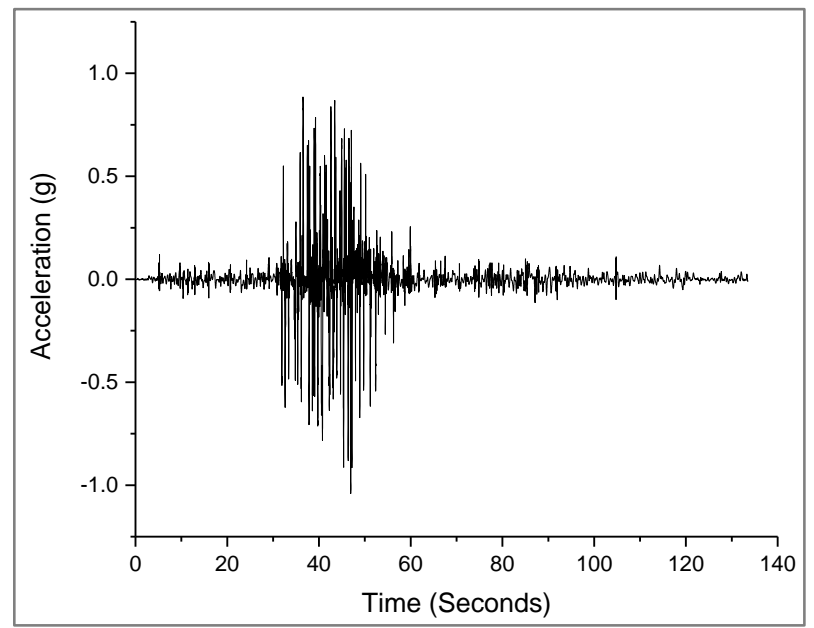

Figure 19. Time History of Bhuj Earthquake (N78E)

The dynamic response to the time history data was extracted to relate the fixed base and SSI effects. The top storey response of Fixed base model and SSI model are plotted, as shown in Figure 20. From the plot, it can be observed that SSI model shows an increase in the response to fixed base model because of kinematic and inertial Interactions.

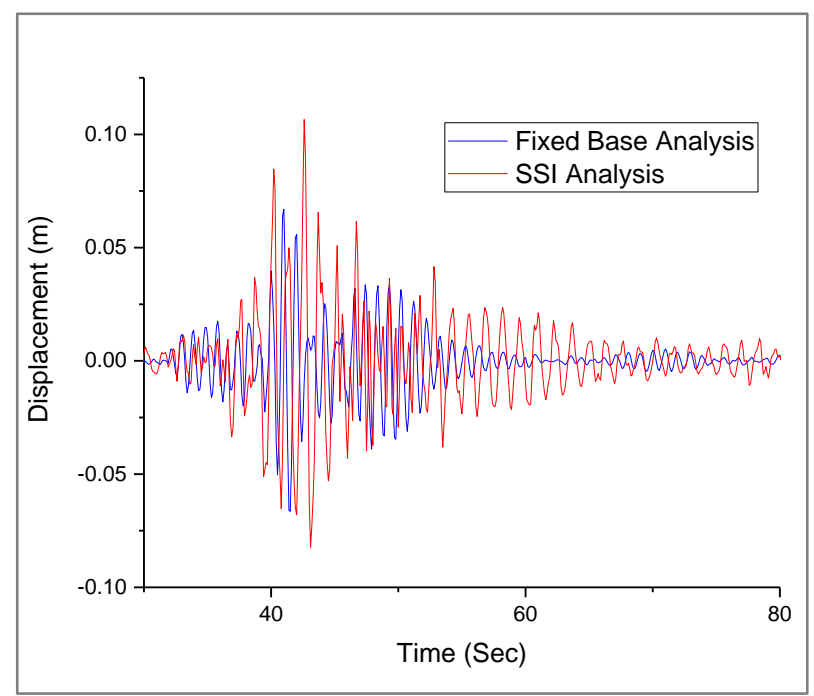

Figure 20. Comparison of Top Storey Response Fixed base and SSI System Under Time History of Bhuj Earthquake

The response of the earthquake data clearly indicates around 53\% increase in the response of the SSI over fixed base condition similar to that of the experimental analysis. The predominant time period and mean period for earthquake data is 0.26 and 0.59 seconds respectively, which does not coincide with the natural period of the system, hence top storey displacement due to earthquake load is less than that of maximum displacement for harmonic excitation at resonance condition. It is evident from the results that the response of the soil pile structure system has increased significantly compared to the fixed base condition which will change the performance level of the building leading towards the collapse of the structure

To understand the effect of the number of bays and the height of the structure in the seismic response of the building, building frame with one bay, two bays (in both directions), and three bays (in both directions) were analyzed for both fixed base and flexible base, as shown in Figure 21. The analysis was carried out considering 5, $10 \& 15$ storey building frames with a typical storey height of $3 \mathrm{~m}$. The stiffness of the structural elements was kept constant. 3-Dimensional models with fixed and SSI models with pile foundation were modelled in SAP 2000. Equivalent static analysis as per Is 1893 (2016) [23] codal provisions were carried out and the response of the building frames for zone-V and Soil type-III for fixed and SSI conditions are determined. 


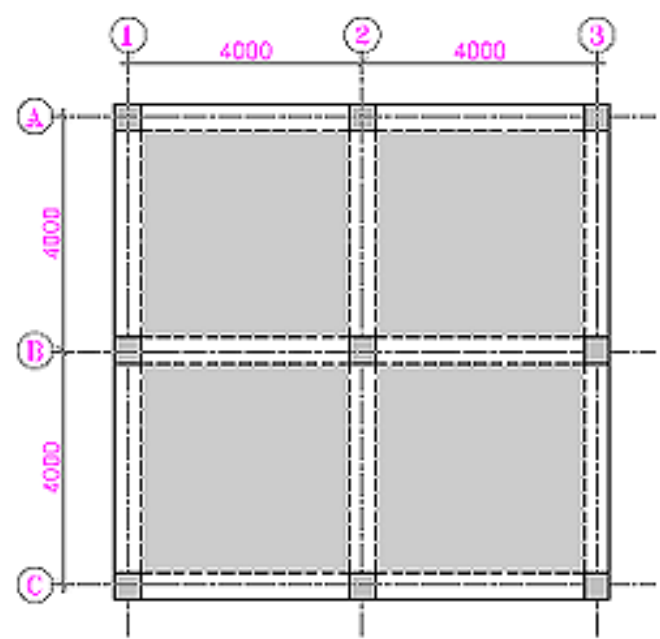

(b)

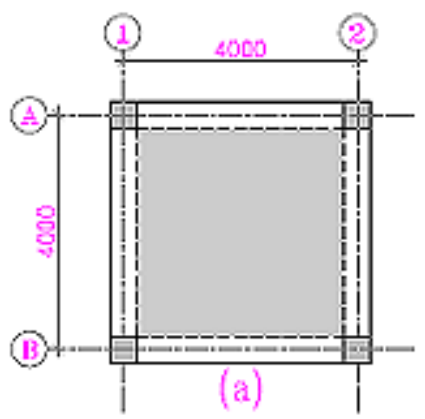

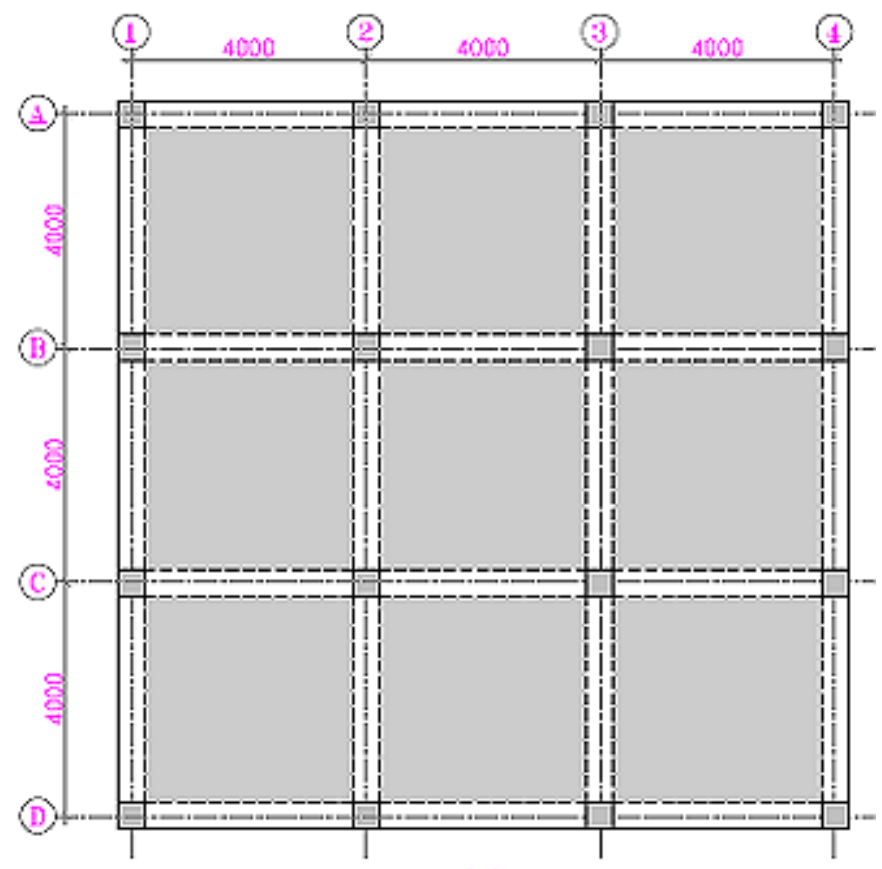

(c)

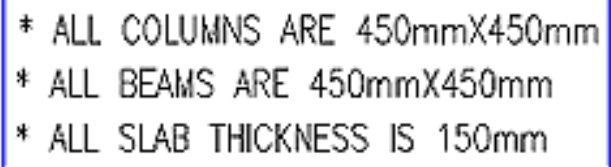

Figure 21. plan of (a) one bay Building Frame (b) Two bay Building Frame (c) Three bay Building Frame

Table 5. Time period of Building frames (fixed and SSI)

\begin{tabular}{ccccccc}
\hline & \multicolumn{4}{c}{ Time period in Seconds } \\
\hline parameters & Building frame with one bay & \multicolumn{2}{c}{$\begin{array}{c}\text { Building frame with two bays in } \\
\text { both directions }\end{array}$} & $\begin{array}{c}\text { Building frame with three bays in } \\
\text { both directions }\end{array}$ \\
& Fixed base & SSI & Fixed base & SSI & Fixed base \\
\hline 5 storey model & 0.47 & 0.72 & 0.48 & 0.72 & 0.495 \\
10 Storey Model & 0.98 & 1.37 & 1.01 & 1.45 & 1.02 \\
15 Storey Model & 1.67 & 2.04 & 1.60 & 2.08 & 1.41 \\
\hline
\end{tabular}

Table 6. Top Storey Displacement (fixed and SSI)

\begin{tabular}{|c|c|c|c|c|c|c|}
\hline \multirow{3}{*}{ parameters } & \multicolumn{6}{|c|}{ Top Storey Displacement in $\mathbf{~ m m}$} \\
\hline & \multicolumn{2}{|c|}{ Building frame with one bay } & \multicolumn{2}{|c|}{$\begin{array}{l}\text { Building frame with two bays in } \\
\text { both directions }\end{array}$} & \multicolumn{2}{|c|}{$\begin{array}{l}\text { Building frame with three bays in } \\
\text { both directions }\end{array}$} \\
\hline & Fixed base & SSI & Fixed base & SSI & Fixed base & SSI \\
\hline 5 storey model & 14.8 & 28.6 & 13.7 & 25.3 & 14.3 & 26.5 \\
\hline 10 Storey Model & 43.9 & 112.2 & 42.9 & 124.4 & 42.4 & 114.8 \\
\hline 15 Storey Model & 80.8 & 289.2 & 72.5 & 277.8 & 69.6 & 246.8 \\
\hline
\end{tabular}

From Table 5 and Table 6, it can be observed that the number of bays does not significantly affect the time period and frequency of the building frames but the height of the structure shows a significant effect on the dynamic property of the structure as well as the response for both fixed and SSI condition. The increase in response is observed in SSI condition compared to that of fixed base, as the height increases the amplification of response has also increased.

\section{Conclusions}

In this study, an effort has been made to investigate the effect of soil pile structure system on its seismic behaviour. Shake table tests were conducted on a scaled model with fixed base condition and with floating piles embedded in soft clay. Numerical modelling and analysis were also carried out and are compared with experimental results. Based on the results from the experiments, it can 
be seen that the soil pile system will alter the dynamic properties and behaviour of the building. The lateral deflection of the building was amplified in case of building resting on soil pile system in comparison with fixed base condition indicating the dominant role of foundation and subsoil on the structure. The increased storey drift and the lateral displacements for Soil pile structure system is the combined effect of soil amplification and rocking component. The increased lateral displacements will also increase the bending moment acting at the foundation.

The response of building frames with varying height and lateral dimension of the building were analyzed numerically for both fixed and SSI with pile foundation in order to assess the effect of building configuration for seismic loading. I $t$ is observed that the number of bays does not significantly affect the time period and frequency of the building frames but the height of the structure shows a significant effect on the dynamic property of the structure as well as the response for both fixed and SSI condition. As the height increases the amplification of response also increases. The increased response of the Soil pile structure system can change the performance level of the building leading towards collapse. Hence it is more realistic to consider the soil foundation structure system in the analysis and design of buildings resting on soft soil.

\section{Acknowledgement}

Authors sincerely thank the authorities of Central Power Research Institute, Bangalore and Department of Civil Engineering, UVCE, Bangalore University, Bangalore, for extending the earthquake laboratory facility for the research work. Also thank Dr. S V Dinesh, Professor \& Head, SIT, Tumkur for extending support in conducting the research.

\section{REFERENCES}

[1] Eduardo Kausel, "Early History of Soil-Structure Interaction", Journal of Soil Dynamics and Earthquake Engineering 30 (2010) 822-832

[2] Jose M. Roesset, "Soil Structure Interaction the Early Stages", Journal of Applied Science and Engineering, Vol. 16, No. 1, pp. 1_8 (2013)

[3] Sushma. Pulikanti, and P. Ramchandra, "SSI Analysis of framed structure supported on pile foundation with and without interface element", FGE Report no IIIT/TR/2014/1

[4] Tabatabaiefar, H.R., Fatahi, B. \& Samali, B.,'An Empirical Relationship to Determine Lateral Seismic Response of Mid-Rise Building Frames under Influence of Soil-Structure Interaction', The Structural Design of Tall and Special
Buildings;2012; vol 23, 526-548

[5] Hamid Reza Tabatabaiefar \& Ali Massumi, "A Simplified Method to Determine Seismic Responses of Reinforced Concrete Moment Resisting Building Frames Under Influence of Soil-Structure Interaction", Soil Dynamics and Earthquake Engineering 30 (2010) 1259-1267

[6] Durante MG, Sarno L, Mylonakis G, Taylor CA, Simonelli AL. "Soil-pile-structure interaction: experimental outcomes from shaking table tests". Earthquake Engineering \& Structural Dynamics 2015;45(7):1041-61.

[7] SureshR.Dash, L.Govindaraju \& SubhamoyBhattacharya, "A Case Study of Damages of the Kandla Port and Customs Office Tower Supported on a Mat- Pile Foundation in Liquefied Soils Under the 2001 Bhuj Earthquake", Soil Dynamics and Earthquake Engineering 29 (2009) 333-346

[8] Subhamoy Bhattacharya , Domenico Lombardi , Luiza Dihoru , Matt S. Dietz, Adam J. Crewe, and Colin A. Taylor "CH.8 Model Container Design for Soil-Structure Interaction Studies" Role of Seismic Testing Facilities in Performance-Based Earthquake Engineering: SERIES Workshop, Geotechnical, Geological and Earthquake Engineering 22, DOI 10.1007/978-94-007-1977-4_8,(C) Springer Science+Business Media B.V. 2012

[9] Hussien MN, Tobita T, Iai S \& Karray M. "Soil-pile-structure kinematic and inertial interaction observed in geotechnical centrifuge experiments". Soil Dyn Earthq Eng 2016;89:75-84.

[10] Subhamoy Bhattacharya, Fabrizio Scarpa \& Matteo Bianchi, "Dynamic Response of a Geotechnical Rigid Model Container with Absorbing Boundaries", Soil Dynamics and Earthquake Engineering, Volume 69, February 2015, Pages 46-56

[11] Lu, X., Li P., Chen Y. \& Chen B, 2004, 'Shaking Table Model Testing on Dynamic Soil-Structure Interaction System', Proceedings of the 13th World Conference on Earthquake Engineering Vancouver, B.C., Canada, August 1-6, 2004, Paper No. 3231.

[12] Boulanger RW, Curras CJ, Kutter BL, Wilson DW, \& Abghari A, "Seismic soil-pile structure interaction experiments and analyses". J Geotech Geoenviron Eng 1999;125(9):750-759

[13] Meymand, P.J., Riemer, M. \& Seed, R.B. 2000, 'Large Scale Shaking Table Tests of Seismic Soil-Pile Interaction in Soft Clay', Proceeding of the 12th world Congress on Earthquake Engineering, Paper no. 0915.

[14] Aslan S. Hokmabadi, Behzad Fatahi and Bijan Samali (2014) "Physical Modeling of Seismic Soil-Pile-Structure Interaction for Buildings on Soft Soils", ASCE, ISSN 1532-3641/04014046(18)

[15] Dimitris Pitilakis, Matt Dietz, David Muir Wood, Didier Clouteau and Arezou Modaressi, "Numerical Simulation of Dynamic Soil-Structure Interaction in Shaking Table Testing", Soil Dynamics and Earthquake Engineering 28 (2008) 453-467

[16] FEMA 356(2000), Prestandard and Commentry for the Seismic Rehabiliatation of Buildings, Federal Emergency Management Agency, Building Seismic Safety Council, Washinton, D.C. 
[17] Harris, H.G. \& Sabnis, G.M. 2000, "Structural Modeling and Experimental Techniques, 2nd edition, Boca Raton, CRC Press

[18] Sushma. Pulikanti, and P. Ramchandra, "SSI Analysis of Framed Structure Supported on Pile Foundation with and Without Interface Element", FGE Report no IIIT/TR/2014/-1.

[19] Martakis P, Taeseri D, Chatzi E \&Laue J. "A centrifuge-based experimental verification of soil-structure interaction effects". Soil Dynamics \& Earthquake Engineering 2017;103:1-14.

[20] Zanganeh A, Svedholm C, Andersson A, Pacoste C \&Karoumi R. "Identification of soil-structure interaction effect in a portal frame railway bridge through full-scale dynamic testing". Engineering Structures 2018;159:299 309

[21] Goit C. S., Saitoh M., Kawakami H. and Nishiyama S.,
"Experimental Studies On Non-Linear Response Of Soil-Pile-Structure Systems Subjected To Strong Ground Motion", The 14 th World Conference on Earthquake Engineering October 12-17, 2008, Beijing, China

[22] Moss, R. E., Crosariol, V., and Kuo, S. (2010). "Shake Table Testing to Quantify Seismic Soil Structure Interaction of Underground Structures." Proc., Int. Conf. on Recent Advances in Geotechnical Earthquake Engineering and Soil Dynamics, Univ. of Missouri.

[23] IS 1893," Criteria for Earthquake Resistant Design of Structures", Bureau of Indian Standards, 2016.

[24] Cai, Y. X., Gould, P. L. and Desai, C. S. "Nonlinear Analysis of 3D Seismic Interaction of Soil - Pile Structure Systems and Application." Engineering Structures 22, 191 - 199, 2000.

[25] Chore, H. S. and Ingle, R. K. "Interaction analysis of building frame supported on pile group." Indian Geotech. Journal, (4), 483-501, 2008 